\title{
Estudio histórico-artístico de la Torre de la Merced de Rota (Cádiz)
}

\author{
Historical-artistic study of the Merced's \\ Tower in Rota (Cádiz)
}

\author{
Francisco Javier Monclova González \\ Doctor en Historia del Arte \\ ID ORCID 0000-0003-2549-0707
}

\begin{abstract}
Resumen: La Torre de la Merced es uno de los escasos restos del desaparecido convento mercedario de Rota. El artículo trata los aspectos constructivos y de estilo, aportando una hipótesis de autoría en la figura del arquitecto Alonso Moreno. Por último, se realiza la descripción del edificio en su estado actual.
\end{abstract}

Palabras clave: Rota, Arquitectura, Torre de la Merced, Alonso Moreno.

\begin{abstract}
The Merced's Tower is one of the few rests of the primitive convent in the ville of Rota. In this paper we analyse aspects about the construction and style, suggesting Alonso Moreno as the possible author. Also we study other aspects about the state of the construction nowadadys.
\end{abstract}

Keywords: Rota, Arquitecture, Merced's Tower, Alonso Moreno.

\section{INTRODUCCIÓN}

La Torre de la Merced es, sin duda alguna, uno de los monumentos más conocidos y destacados de esta bella localidad de la costa gaditana. Constituye el principal resto arquitectónico, junto con una pequeña sala y dos capillas anejas, del desaparecido convento masculino de la Orden de la Merced Descalza. Abordar el estudio del citado monumento presenta a priori una serie de importantes dificultades a solventar. En primer lugar, nos encontramos hoy con una construcción prácticamente exenta debido a la desaparición casi absoluta del edificio conventual al que pertenecía, circunstancia que impide valorar la obra arquitectónica dentro de su conjunto. Por otro lado, las fuentes documentales son escasas y un tanto imprecisas, puesto que desconocemos muchos aspectos relacionados con su planteamiento, edificación, autoría y otros, cuyo conocimiento, facilitaría un análisis de mayor calado y trascendencia. En este sentido, hemos de indicar 
que los libros de actas capitulares del cabildo del Archivo Municipal comienzan en 1742, fechas muy posteriores a la construcción de la torre. La documentación relativa al Convento de la Merced Descalza se conserva en el Archivo Histórico Nacional, de la cual, traemos ahora algunos documentos relativos a la torre a los que se hará referencia en el cuerpo del trabajo. Por último, era necesario dilucidar la originalidad del proyecto a causa de los importantes procesos restauradores a los que ha sido sometida la arquitectura objeto de estudio. Este conjunto de aspectos pueden explicar en buena medida el vacío historiográfico y la ausencia de estudios relativos a la torre mercedaria.

El motivo principal de nuestro trabajo no es otro que realizar una aproximación al significado histórico y artístico de la torre mercedaria partiendo, como es lógico, de los escritos que nos han precedido y de los que todos somos deudores, pero atendiendo además a nuevas cuestiones. Desde el inicio de la tarea observamos la necesidad de realizar un estudio que permitiera comprender las diferentes circunstancias que afectaron a la edificación, incidiendo en aspectos de índole cronológico y acotando las fechas de su erección. También juzgamos de valor establecer el contexto estilístico y estético de la obra, marcada por postulados clasicistas pese a su cronología plenamente barroca. En este sentido incluimos un análisis estilístico y una hipótesis de autoría del monumento en cuestión. Seguidamente, analizamos sus formas y aportamos todos aquellos testimonios encontrados sobre sus restauraciones. En relación con este último aspecto desglosamos la información obtenida de los fondos del Archivo Municipal de Rota, de enorme validez a la hora de valorar de manera crítica los debes y haberes de las restauraciones a las que se somete a la torre en 1972, 1986 y 2009. Finalmente, unas breves conclusiones ponen término a nuestra labor.

\section{EL ESTADO DE LA CUESTIÓN}

La historia del desaparecido Convento de la Merced ha sido reconstruida en diversos estudios, los cuales, contrastan con la escasez de trabajos realizados desde la perspectiva de la historia del arte. De todos modos, es injusto no valorar de forma adecuada las aportaciones de aquellos que nos precedieron en el tiempo y que pusieron toda su dedicación y empeño en recuperar la historia del citado monumento. 
Entre los primeros, hemos de destacar, la completa investigación publicada en 1971 por Antonio García de Quirós Milán, cronista oficial de la villa, con el título Historia de la Ermita y Cofradía de la Vera Cruz. La obra suscita un enorme interés y resulta de imprescindible consulta para el conocimiento y estudio del pasado histórico de Rota. El hilo conductor de todo el libro trata de reflejar el origen e historia de la antigua ermita, donada por la hermandad para la fundación del convento mercedario en 1604. El ilustre cronista dedica unas páginas a la torre mercedaria dentro de tan extenso y documentado libro. Utilizando un tono poético y ciertamente nostálgico, aporta datos de interés relacionados con el objeto de nuestro estudio. El autor señala como la actual torre es una "joya dieciochesca" reconstruida tras el terrible huracán que azotó Rota el día veintiséis de octubre de 1722, cuya fuerza destructiva fue tal "que derrumbó la torre del convento". Añade que, de forma rápida, fue reconstruida procurando "restablecer su primitiva arquitectura", dando por concluida una torre de "severa y sólida esbeltez". También aporta una breve descripción de la edificación y algunos apuntes históricos que afectaron a la torre en diversas fechas. Más adelante narra el proceso de adquisición de la torre por parte del Ayuntamiento en 1957. De mayor relevancia son las noticias relativas a la importante restauración practicada en la torre a principios de los pasados años setenta. Sobre este aspecto, el Cronista se muestra satisfecho con el citado proceso restaurador. Por último se incluye en la obra una fotografía del estado de la torre antes de su restauración, dando por concluidas las páginas dedicadas al monumento con la misma sensibilidad poética que impregna toda la obra.

Algunos años más tarde, en 1981, José Luis de la Rosa Domínguez realiza una nueva aproximación a la historia local en El Convento de la Merced de Rota y la Virgen de la Escalera. El trabajo versa sobre aspectos históricos del convento mercedario que se completa con el estudio de la antigua devoción mariana. Las páginas dedicadas a la Torre de la Merced son deudoras en lo relativo a datos históricos de la obra de García de Quirós. Interesantes resultan las láminas fotográficas que incluye el libro, en las que se puede observar la torre antes y después de la restauración de 1972, así como la placa y el escudo mercedario, ambos existentes actualmente en la edificación.

Con posterioridad, se publica en 1995 la obra Estancias en Rota con el sugerente subtítulo de Historia de la Villa a través de sus monumentos 
o Habitar después de entonces de Mariano Pérez Humanes. El estudio contribuye en buena manera al conocimiento patrimonial, arquitectónico y urbano de Rota. Dedica un extenso capítulo al convento mercedario, ampliamente ilustrado, concretando sus orígenes, momento de construcción, su ubicación dentro de la villa, la arquitectura y, por último, exclaustración, demolición y usos del solar. Tiene gran valor la reconstrucción que realiza del edificio conventual incluyendo una planta detallada de todo el conjunto a modo de hipótesis personal. También presenta diversos testimonios fotográficos de algunas dependencias conventuales antes de ser derribadas. Sin embargo, en lo concerniente a los datos sobre la torre bebe en las fuentes de los autores citados anteriormente.

En último lugar, que no en importancia, hemos de valorar las aportaciones al tema en cuestión presentadas por Don José Antonio Martínez Ramos, condensados en sus Anales de la Villa de Rota. El señor Martínez Ramos ha trascrito la información ofrecida por documentos, libros y papeles del desparecido convento mercedario conservados en el Archivo Histórico Nacional, entre los que se encuentra valiosa información relativa a la torre. Los documentos estudiados hacen referencia a la ruina de la torre a causa del fuerte temporal de 1722 así como datos sobre su reconstrucción entre los años 1722 y 1724. También añade en sus Anales otras informaciones y datos sobre la adquisición de la torre por el Ayuntamiento y otros aspectos relacionados con la restauración llevada a cabo en 1986.

\section{LA TORRE}

\subsection{Su construcción}

La fundación del Convento de la Merced de Rota tiene lugar el día veintiséis de octubre de 1604 en la ermita de la Vera Cruz. A pesar de ser una obra de nueva planta y que, lógicamente, hubo de haberse planificado como una obra terminada en su conjunto, el edificio conventual fue surgiendo de los diferentes añadidos que temporalmente se le iban haciendo. Entre los condicionantes que impidieron realizar la edificación de una manera continuada estaban su propio origen, sito en una primitiva ermita, hecho que también determinó su forma inicial. Por otro lado, la orden religiosa no era propietaria de los terrenos anejos a la ermita debiendo esperar a las donaciones de 
particulares para poder edificar nuevas dependencias conventuales. Un último problema fueron los condicionantes económicos, muy críticos y propios de un contexto histórico poco propicio para grandes gastos y empeños. Finalmente se llegó al término del proceso constructivo y el edificio conventual quedó concluido en 1624. En virtud de estos datos, podemos deducir que la primitiva Torre de la Merced hubo de edificar entre 1604 y 1624 resultando imposible concretar en mayor medida los años exactos en que pudo elevarse. No conocemos descripción alguna de la misma, aunque algunos autores señalan que "tenía una forma y decoración similar a la actual" dentro del llamado "estilo desornamentado" o"postherreriano"1.

El día veintiséis de octubre de 1722, curiosamente ciento dieciocho años después de su fundación, un terrible temporal azotó las costas gaditanas y onubenses, causando graves daños y espanto entre los vecinos de muchas poblaciones de la costa atlántica andaluza, dejando tras de si un importante saldo de destrucción y ruina desde un punto de vista arquitectónico. El temporal trajo fatales consecuencias para Rota, entre ellas, la ruina de la torre conventual. Los destrozos debieron ser importantes, sin duda, afectando de manera especial al campanario quedando el convento más de un año sin sitio en donde poner las campanas ${ }^{2}$. Un interesante testimonio de aquella época está recogido en uno de los libros de bautismos de la parroquia de la $\mathrm{O}$ indicando lo siguiente:"Lunes 26 de octubre de 1722. Este día por la mañana se perdió el barco de Luis Rodríguez, donde se ahogaron cuatro personas y se salvaron dos. La torre del convento de esta villa se cayó con la fuerza del huracán"

Es difícil poder certificar el grado de destrucción causado por el huracán a tenor del único testimonio documental conocido y que acabamos de citar. Es lógico pensar, por otra parte, que la zona superior de la torre campanario sería la más perjudicada e incluso pudo ser derribada casi con toda seguridad. Otro problema añadido es la

PÉREZ HUMANES, M. Estancias en Rota. 1995, p. 78.

2 MARTÍNEZ RAMOS, José Antonio. Anales de la Villa de Rota. Los datos están extraídos del Archivo Histórico Nacional, Clero, Papeles del Convento de la Merced, legajo 1730/2. GARCÍA DE QUIRÓS, Antonio. Historia de la Ermita Cofradía de la Vera Cruz. Rota, 1974, p.169.

3 Archivo parroquial de la O. Libros de bautismos, libro 20, folio 41. Agradecemos a Don José Antonio Martínez Ramos la amabilidad que ha tenido en facilitarnos esta noticia. 
falta de constancia documental sobre su reconstrucción, que pudo ser parcial o total elevándose de nueva planta. En este sentido, nos decantamos por una reconstrucción integral que afectaría tanto a los cuerpos de campanas como al refuerzo de su estructura, aunque quizás no fuese necesario su reinicio desde los cimientos.

Meses más tarde, en 1723, el comendador y religiosos de la comunidad del convento mercedarios descalzos de Rota señalaban que, para afrontar la ruina de la torre a causa del temporal, serían necesarios más de dos mil pesos escudos para reedificarla según el parecer de los alarifes. Se añade que dicho convento no puede costear dicha obra debido a su pobreza y atraso, debiendo apelar a la piedad de los fieles. La documentación hace constar el interés de algunos fieles y devotos por colaborar en la empresa de reconstrucción, haciendo propuesta de la entrega de diez pesos escudos de plata a condición de que la comunidad de religiosos asistiera al entierro y sufragio de dos de los miembros de cada familia donante, cantando la vigilia y responso. La propuesta fue aceptada entre los concurrentes elevando la petición al padre provincial, el cual, concedió licencia pertinente para ello ${ }^{4}$.

Para su construcción se empleo la piedra como elemento material de primer orden. Con el fin de obtenerla, el Padre Comendador del convento solicitó del Cabildo la extracción de piedras de la playa de Levante. El Cabildo concedió su autorización indicando el lugar de Bahifora como el más indicado para la extracción del material ${ }^{5}$.

Las obras de reconstrucción debieron suceder durante el año de 1723 para darse por concluidas en los primeros meses de 1724. Existe constancia documental de asientos relativos a gastos de la obra de construcción de la torre. Así, el once de mayo de 1724 se dieron por gastados un montante de 17.117 reales, de los cuales, 2.800 fueron de dos campanas nuevas que se compraron de limosna ${ }^{6}$.

Por último y en relación con la época de su construcción, García de Quirós señala que por aquellos años ostentaba el cargo de corregidor Don Fernando Vázquez Mancheño, siendo señor de la villa

4 MARTÍNEZ RAMOS, José Antonio. Anales... A.H.N. Clero, Papeles del Convento de la Merced, legajo 1730/2.

5 GARCÍA DE QUIRÓS, Antonio. Historia de la Ermita... p. 169.

6 MARTÍNEZ RAMOS, José Antonio. Anales... A.H.N. Clero, Libro 2079, Rota, Mercedarios Descalzos de laVera Cruz. Libro de recibo y gasto común. 1709-1726. 
Don Joaquín Guadalupe Ponce de León, séptimo Duque de Arcos, fallecido el 18 de marzo de $1729^{7}$.

Poco más sabemos de la historia de esta torre. Las siguientes noticias nos remiten al siglo XIX. Las crónicas señalan como el día 15 de marzo de 1833 un rayo alcanzó la torre destruyendo la linterna de cantería que remataba la cúpula. Esta linterna se hallaba coronada por una artística cruz de hierro forjado y una veleta igualmente metálica ${ }^{8}$. El convento mercedario fue clausurado por efecto de las leyes desamortizadoras dictadas por Mendizábal, siendo la comunidad forzosamente exclaustrada a principios de $1836^{9}$. Este lamentable suceso provocó el abandono del inmueble hasta su casi total ruina años más tarde. Los restos del convento pasaron a propiedad municipal a partir del 27 de febrero de 1850 en virtud de la orden de concesión dictada desde la Dirección General de Fincas del Estado. Sin embargo, estos trámites sufrían largas demoras debido a la necesidad, en numerosos casos, de una aceptación eclesiástica. En 1860 la iglesia conventual constaba como propiedad exclusiva del arzobispado hispalense, hasta que en 1909 el ruinoso estado de la misma aconsejó su cesión al Ayuntamiento, excluyendo en la misma los cuarenta y ocho metros cuadrados del solar adquirido por Don Eleuterio Ruiz Mateos ${ }^{10}$.

En 1957 se produce la adquisición de la Torre de la Merced por parte de la Corporación Municipal. La propuesta se realiza a instancias del propio alcalde Don Antonio García de Quirós Milán, siendo tratada en el punto siete de la sesión plenaria celebrada el día primero de febrero de aquel año y acordada por unanimidad. La compra de la arquitectura se fijó en quince mil pesetas que se abonaron a su último propietario Don Isidoro Ruiz Mateos Requejo ${ }^{11}$. La alcaldía manifestó que se tenía convenida su compra directa, sin subasta ni concurso, libre de carga y gravámenes. La adquisición de la torre por el municipio de Rota tuvo por objeto su conservación como monumento característico y representativo de la Villa ${ }^{12}$.

\footnotetext{
Historia de la Ermita...p.172.

GARCÍA DE QUIRÓS, Antonio. Historia de la Ermita...p. 169.

GARCÍA DE QUIRÓS, Antonio. Historia de la Ermita... p. 122-124.

PÉREZ HUMANES, Mariano. Estancias en Rota... p. 87-88.

GARCÍA DE QUIRÓS, Antonio. Historia de la Ermita... p. 170.

MARTÍNEZ RAMOS, José Antonio. Anales... Año de 1957.
} 


\subsection{Análisis estilístico}

La Torre de la Merced es uno de los mejores ejemplos de la arquitectura realizada en Rota durante el siglo XVIII. La obra se engloba dentro de un Barroco clásico, el cual, otorga mayor protagonismo al lenguaje de los órdenes arquitectónicos, de los que emana la auténtica belleza de los edificios, por encima del ornato superfluo o la decoración exuberante. Esta postura difiere del llamado Barroco castizo representado por los grandes maestros del barroco hispano como Figueroa, Hurtado Izquierdo, Churriguera, Tomé o Ribera entre otros.

El análisis estilístico de la arquitectura conventual de la Torre de la Merced Descalza de Rota implica una aproximación y conocimiento de la arquitectura y los tratados de los siglos XVI y XVII. A esta circunstancia también hemos de sumar la influencia que en la obra estudiada se observa de grandes maestros de la arquitectura española inmediatamente anterior como es el caso de Alonso Cano.

Deteniéndonos en el inicio del análisis, hemos de señalar de forma breve, como dentro de los materiales utilizados en la construcción, el uso de la piedra no fue frecuente en la época por constituir un elemento de lujo. Sin embargo, en el caso y lugar que nos ocupa, hubo la suerte de gozar con la posibilidad de obtenerla producto de las canteras locales como acreditan las fuentes, en la playa de Levante en el lugar conocido como Bahifora. Por otra parte, el encalado de la caña de la torre permite un leve juego de bicromía, entre el blanco de la cal y la amarillenta piedra, muy utilizado en la arquitectura barroca. Además, los sillares que refuerzan las aristas de la torre nos recuerdan una cierta arquitectura purista de la primera mitad del siglo XVII.

El autor de la Torre de la Merced debió de tener sólidos conocimientos de la arquitectura clasicista española de siglos pasados. Esta herencia clasicista o purista de nuestro autor se pone de manifiesto en el uso de los órdenes esquematizados, el juego de pilastras pareadas flanqueando el vano y los remates de plintos. A ello podemos añadir la presencia de una decoración de finas molduras de ligero resalte o, por el contrario, dejando la arquitectura desnuda con paneles lisos que conforman un edificio elegante y severo con una marcada austeridad en lo decorativo.

Es lógico pensar que su autor conocía los tratados de arquitectura de los siglos XVI y XVII. Observando los cuerpos de campanas de la torre mercedaria es incuestionable la relación entre arquitectura y 
tratados. El primero de los cuerpos del campanario presenta un juego de dobles pilastras y vano de medio punto claramente inspirado en Vignola. Por otro lado, el segundo campanario reproduce de modo sucinto parte del módulo clásico de Andrea Palladio, que consiste en reproducir un arco o vano de medio punto flanqueado por óculos. Finalmente, de Sebastiano Serlio se propone el juego del resalto de los elementos constructivos, entre los que destacamos el uso de la cadeneta que cumple una doble función decorativa y estructural. También se deja sentir en la torre mercedaria la huella de Alonso Cano y el conocimiento que el tracista tiene de su obra al utilizar el modelo de pilastras cajeadas tan características en la arquitectura del maestro granadino.

Nuestro arquitecto se encontraba además familiarizado con la tradición. En este sentido, vemos como recurre a la cerámica vidriada con la característica combinación de azul cobalto y blanco, utilizada como apliques incrustados, en esta ocasión, en la cúpula que cubre la torre. Resulta conocida la gran influencia de la cerámica sevillana en Rota, de la que hoy se conserva algún ejemplo destacado, producto de la larga tradición de siglos de los obradores del barrio de Triana. Otro matiz de la tradición arquitectónica hispana reside en las finas molduras que decoran los vanos del segundo cuerpo de campanas que recuerdan, en el mejor de los sentidos, a los alfices hispanomusulmanes.

Tampoco debemos olvidar ahora la concreción de los aspectos barrocos de la obra que justifican su inclusión en el estilo. Así podemos señalar el juego de cuerpos en el campanario de diferente sección creando una variedad de perfiles en la arquitectura; la combinación de vanos aunque sin alterar los modelos clasicistas y la leve bicromía producto de los diferentes materiales y acabados, son breve ejemplo del estilo. A ello añadimos otra constante barroca como es el uso del azulejo, que aquí recubría cúpula y linterna con una temática original de elementos geométricos y símbolos religiosos, hoy tristemente desaparecidos. Con respecto a la cúpula su utilización puede entenderse como una concesión al contexto barroco propiamente andaluz, a pesar de que la configuración de la misma en la actualidad diste en parte del modelo diseñado originalmente.

En conclusión, el autor de la torre mercedaria fue un arquitecto con conocimiento de los tratados italianos y españoles del Renacimiento y de la arquitectura clasicista española de los siglos 
XVI y XVII. También demuestra su saber sobre el uso y tratamiento de materiales diversos, en especial la piedra y el trabajo de cantería, y las manifestaciones de la tradición artesanal. Por último, su obra se integra plenamente en la realidad artística y arquitectónica de aquella época.

\subsection{Hipótesis de autor: Alonso Moreno}

A la hora de concretar la autoría de la obra objeto de estudio nos topamos con la dificultad de no existir referentes documentales del autor ni tampoco se conoce hipótesis alguna al respecto de las trazas y realización de la Torre de la Merced. Sin embargo, nosotros queremos plantear a continuación una hipótesis de autoría atendiendo a la descripción formal de la arquitectura y a su composición general, pudiendo establecer una serie de premisas que nos permitan dibujar un perfil artístico de su autor o tracista. En definitiva, intentaremos explicar todos aquellos aspectos que la obra nos dice de su autor.

La fábrica de la Torre de la Merced proclama una práctica arquitectónica clasicista cercana a las influencias generadas desde la Corte madrileña y escasamente ligada al contexto cultural andaluz de aquella época. Este repertorio de formas y estilo fueron difundidos en Andalucía por diversos arquitectos seguidores de Alonso Cano en mayor o menor medida. Muchos de ellos reflejan en sus obras la evidente puesta en práctica de los tratados venidos de Italia sin olvidarnos tampoco de la obra del agustino Fray Lorenzo de San Nicolás.

Esta premisa expuesta más arriba cobra sentido en la obra de Alonso Moreno. Citado este nombre es ahora cuando llega el momento de concretar nuestra hipótesis de trabajo, la cual, pretende establecer una conexión entre la torre mercedaria de Rota y la obra del arquitecto Alonso Moreno (1640 -1725) Maestro Mayor de obras de la casa ducal de Arcos. El nombre de Alonso Moreno y su formación están ligados al arquitecto de origen italiano Bartolomé Zumbigo que gozó de un merecido prestigio en la época que le tocó vivir. Sirva de muestra su participación en los arreglos y reparos de las techumbres de El Escorial en 1671. La dimensión profesional del citado arquitecto aumentaría al ser nombrado ese mismo año maestro mayor de la Iglesia de Toledo. El ejercicio de mencionado cargo le procura diversos trabajos dentro de la diócesis primada y también le permite viajar a distintos lugares de España para dar su autorizado parecer a 
la construcción de importantes edificios del momento. En tierras de Andalucía visitará dos relevantes obras como son las fachadas de la Catedral de Granada diseñada por Alonso Cano y de la Catedral de Jaén con trazas de López de Rojas. La dilatada experiencia y reputación profesional de Bartolomé Zumbigo son más que suficientes para justificar la petición realizada por el duque de Arcos para hacerse cargo de la planificación de la iglesia de San Agustín de Marchena en 1680. El templo estaba destinado a convertirse en panteón familiar, algo que no vería más que en sus comienzos al fallecer en Toledo dos años mas tarde. Es desde ese momento cuando Alonso Moreno, hombre de confianza y mano derecha del arquitecto, toma las riendas del proyecto trazado por Zumbigo doblemente obligado por los requerimientos del duque y, no menos importante, por completar la obra del que había sido su maestro ${ }^{13}$.

La labor profesional de Alonso Moreno está unida también al mecenazgo de los Duques de Arcos. Para Don Manuel Ponce de León su actividad artística se circunscribe casi por completo a la Iglesia de San Agustín. En 1692 muere Don Manuel, siendo su hijo Don Joaquín quien continúa contando con los servicios y fiel colaboración de Alonso Moreno pero desviando su producción hacia el campo civil. A partir de 1701 el arquitecto tiene a su cargo la obra de reedificación de la Plaza Ducal de Marchena, labor que le mantendrá ocupado hasta 1706. Desde entonces y hasta 1713 dirige la construcción de unas nuevas Casas Capitulares por expreso deseo del Duque ${ }^{14}$.

El conocimiento que Alonso Moreno demuestra de los tratados de arquitectura resulta notable como él mismo expresa en el informe que realiza para la iglesia hispalense del Sagrario. En dichos escritos aporta datos sobre su persona y sobre su categoría profesional, señalando el conocimiento de las obras de Vitruvio, Serlio, Alberti, o Palladio entre otros. Este saber se completa con sus aprendizajes, de primera mano, que tiene de la obra de Fray Lorenzo de San Nicolás, interviniendo en la tasación de las Agustinas de Salamanca de dicho autor. Otro interesante aspecto es la asimilación de diversos elementos tomados de Alonso Cano, hecho que puede explicarse durante

13 RAVÉ PRIETO, Juan Luis. "Arquitectura de ida y vuelta o un enclave canesco cortesano en la campiña sevillana" en Simposium internacional de Alonso Cano y su época. Granada, 2001, pp. 707-719.

14 ARENILLAS, Juan Antonio. Arquitectura civil en Marchena durante el siglo XVIII. 1990, pp. 23-25. 
su colaboración junto a Zumbigo en las obras del Santuario de la Virgen de Atocha de Madrid, a cargo del arquitecto Sebastián Herrera Barnuevo considerado el mejor discípulo de Cano. A todo este acervo profesional, Moreno une su práctica al pie de la obra demostrando una indudable capacidad en la dirección de las mismas. No olvidemos su sólida formación como cantero y el gusto que expresa por los acabados y el juego de texturas tan elocuentes mostrados en la articulación de los paramentos. Todos estos aspectos, aquí brevemente reseñados, pueden contemplarse en la fachada de la iglesia de San Agustín de Marchena, una de sus obras más reconocidas. La historia constructiva de la Iglesia de San Agustín ha sido estudiada por el profesor Ravé Prieto. La numerosa documentación aportada al respecto deja clara la intervención de Moreno respetando las trazas originales de Zumbigo, así como su autoría del diseño de la bella y cortesana portada que hoy podemos contemplar ${ }^{15}$. Esta obra será utilizada como referente del estilo de su autor para establecer paralelismos y puntos de unión entre dicha obra y la Torre de la Merced.

La atribución aquí presentada se basa en la existencia de una triple coincidencia de tipo cronológico, profesional y de estilo. De Alonso Moreno conocemos la fecha de su nacimiento y defunción. La construcción de la Torre de la Merced sorprendería a Moreno con más de ochenta años pero no tenemos ningún indicio que nos haga dudar de su incapacidad para el trabajo. Hemos de suponer que tampoco era necesario su desplazamiento a la localidad gaditana para llevar las riendas de la construcción de manera directa, siendo habitual la delegación en alarifes locales después de haber realizado el planteamiento o proyecto inicial de la nueva obra. También sabemos que a pesar de su longevidad para aquellos años, debió de gozar de buena salud física y mental. Un testimonio de lo que decimos es su visita en 1715, superando los tres cuartos de siglo de vida, a las obras de la parroquia de Santa Cruz de Teba (Málaga), enviado por el Cabildo diocesano con el encargo de inspeccionar dichas obras acompañado del también arquitecto Lorenzo Fernández Iglesias ${ }^{16}$.

15 RAVÉ PRIETO, Juan Luis. "Arquitectura de ida y vuelta o un enclave canesco cortesano en la campiña sevillana" en Simposium internacional de Alonso Cano y su época. Granada, 2001, pp. 707-719.

16 LÁZARO MUÑOZ, María del Prado. El arquitecto sevillano Diego Antonio Díaz. Sevilla: Monte de Piedad y Caja de Ahorros, 1988, p. 39. 
La coincidencia profesional está ligada a su ejercicio y condición de maestro mayor de obras de la Casa de los duques de Arcos en la que trabajó activamente para sus señores, tanto para D. Manuel como para su hijo D. Joaquín Guadalupe Ponce de León, en cuyo señorío se encontraban las villas de Rota y Marchena. Es evidente la colaboración de D. Joaquín en la reconstrucción de la torre mercedaria aunque desconocemos el alcance global de la ayuda. Al menos de manera indirecta resulta probada su aportación cuando el Cabildo de Rota permite la extracción de piedras de las canteras locales con destino a su reedificación, decisión tras la cual no estaría ajena la voluntad del propio duque. En este sentido, no debe extrañar que pudiera ser el propio D. Joaquín quien instara personalmente a su arquitecto para que realizase el proyecto de la nueva obra y de todos aquellos aspectos relacionados con su construcción.

Por último, debe ser el análisis comparado de la obra en estudio con los postulados estilísticos de Alonso Moreno los que puedan establecer un mayor número de nexos entre obra y arquitecto. Adentrándonos en el juego de comparar arquitecturas hemos de relacionar la Torre de la Merced con el diseño de las torres laterales que flanquean la portada de la iglesia de San Agustín de Marchena ejecutadas por Alonso Moreno. Entre estas similitudes señalamos el uso de la cadena de sillares en las aristas de la caña de las torres, la presencia de un modelo de pilastra de fuste cajeado y la impronta compositiva del primer cuerpo de campanas de ambas arquitecturas, evidenciando unas pautas similares y unas mismas fuentes de inspiración.

Finalmente, hemos de concluir que a tenor de los datos conocidos existen elementos de juicio que permiten relacionar y ponen en contacto los postulados estéticos de Alonso Moreno con los aspectos formales y estilísticos reflejados en la Torre de la Merced. Ahora bien, será en último término la aparición de nuevas fuentes documentales las que cuestionen o validen la hipótesis de autoría y atribución aquí expuesta.

\subsection{Descripción}

\subsubsection{El monumento en la actualidad}

Aunque en la actualidad puede ser calificada de arquitectura exenta, la Torre de la Merced se hallaba adosada a la arista sur de la fachada principal del convento, a los pies de la iglesia. La torre presenta el 
siguiente esquema: fuste, dos cuerpos de campanas y cúpula rematada por una pequeña linterna.

La torre presenta unas dimensiones modestas con una altura de 18,54 metros, alejada de las imponentes torres barrocas que serán levantadas a lo largo del siglo XVIII en muchas poblaciones andaluzas. El primer cuerpo o fuste de la torre presenta una altura de 8,45 metros de altura, aproximadamente unas diez varas castellanas de las de entonces, medidas que se observan en otras torres construidas en similar contexto y cronología. Observando la estructura interna de la misma vemos como la caña de la torre se divide en dos alturas o pisos que no trasciende al exterior, pudiéndose usar la parte inferior como dependencia o acceso y una primera planta a la que se accedería por las dependencias conventuales. Esta primera planta se ilumina desde el exterior gracias a un ojo de buey. Le sigue el primer cuerpo de campanas con 4,02 metros de altura siendo algo menor el segundo campanario con 2,62 metros. La torre se cubre con una cúpula de tres metros coronada por un airoso lucernario.

La Torre de la Merced se levanta sobre una sólida base pétrea de mayor grosor y perímetro que la sección de la misma. El uso de sillares favorece el aislamiento de la edificación frente al elevado nivel de humedad propio de su localización costera. La planta baja reutilizada en la actualidad conecta con una sala anexa. La planta primera presenta unas dimensiones casi regulares en su trazado con 4,75 metros en los lados este y oeste por 4,65 metros en los lados norte y sur. El grosor de los muros es considerable alcanzando los 0,82 metros. Los ángulos o aristas de la caña de la torre presentan un aristón o cadena en material de cantería, pétreo, diferente al resto de materiales del fuste con el objetivo de reforzar la construcción. También cumple una función decorativa resaltando las diferencias entre materiales. Esta solución está tomada de Sebastiano Serlio dentro del Libro IV de su Tratado de Arquitectura incidiendo en el aspecto constructivo de refuerzo del paramento y destacando la diferencia de materiales ${ }^{17}$.

En la fachada oeste se abre la única portada de la torre realizada en piedra tallada. Presenta decoración de pilastras de orden toscano en relieve compuestas de base, fuste, capitel y entablamento. Se remata con un frontón triangular partido en su vértice superior. Aprovechando el espacio dejado por el frontón abierto se colocó un

17 AA.VV. Diccionario visual de términos arquitectónicos, Madrid, 2008, p. 79 y 121. 
arco de medio punto cegado enmarcado con su moldura de piedra. Puede tratarse de un antiguo vano de iluminación actualmente ciego, que se ha mantenido así hasta hace pocos años. En dicho espacio se instaló recientemente un pequeño retablo cerámico que reproduce la imagen de la Virgen de la Merced con la siguiente leyenda: "Imagen de Ntra. Sra. de la Merced que se veneraba en el convento de los PP Mercedarios ubicado en este mismo lugar". La portada permite el acceso al interior de la torre, espacio hoy muy modificado, que comunica con otra dependencia posterior utilizada en la actualidad como sede del Consejo de Hermandades y Cofradías de Rota. Por encima de este techo interior se abre, en la misma fachada, un vano ovalado realizado en piedra y cuya función sería dar luz a este tramo de la torre, hoy sin posibilidad de acceso a los pisos superiores. Las fachadas este y sur no presentan decoración alguna. Como dato anecdótico, la torre muestra en su frente occidental la placa con el número diez de la vía urbana en la que se ubica.

En la fachada norte se hallan el escudo de la Merced y una placa marmórea cuya inscripción es la siguiente: TORRE DEL ANTIGUO CONVENTO DE LA MERCED CONSTRUIDA EN 1622 RESTAURADA EN 1972.

El primer cuerpo de campanas arranca de un basamento pétreo y presenta sección cuadrangular continuando el perfil del cuerpo inferior. Este primer cuerpo destinado al albergue de campanas presenta similar diseño en sus cuatro frentes. Sobre el zócalo se levantan cuatro pilastras, presentando fuste cajeado en sus caras norte y oeste, por ser estas las que se mostraban al exterior del complejo conventual, dos a cada lado del vano central sosteniendo un sencillo entablamento. El vano, diseñado a partir de un arco de medio punto, se enmarca por las pilastras pareadas que presentan un fino resalte. El campanario está rematado por una cornisa sobre la que se ubican en cada uno de los ángulos unos plintos que en origen podrían haber estado rematados en pomas o bolas circulares, hoy decorados con jarrones cerámicos.

El segundo cuerpo de campanas está igualmente realizado en cantería pero, a diferencia del anterior, presenta una sección ochavada, con cuatro vanos que coinciden en línea vertical con los del campanario inferior rematados de igual forma en arcos de medio punto. Los vanos se decoran con una fina y elegante moldura en relieve a modo de alfiz, el cual, discurre por toda la mitad superior 
de la oquedad. En las caras de chaflán se abren óculos a medio muro resaltados por finas molduras en todo su perímetro. En la parte superior, la cornisa cierra este segundo campanario. Observando el hueco interior se aprecian unas pequeñas trompas que matan las esquinas y favorecen la sustentación del campanario ochavado.

La cúpula se utiliza como solución práctica de gran belleza para cerrar la construcción que se eleva hasta los tres metros en su punto de mayor altura. Una pequeña linterna rematada con un chapitel añade setenta y cinco centímetros más a la torre mercedaria. Al exterior se reviste de azulejos en blanco y azul con decoración de líneas quebradas colocadas durante la restauración a la que fue sometida la torre en 1986. A tenor de la observación de fotografías antiguas anteriores a esta fecha los azulejos primitivos debieron salir de los talleres alfareros ubicados en el sevillano barrio de Triana con la típica bicromía blanca y azul cobalto de aquellos años. Lo más destacado del conjunto era su variada decoración geométrica y la aparición de imágenes con motivos religiosos como el cáliz y la cruz elevada sobre peldaños o gradas a modo de montículo. Son estos últimos motivos los que dotaban de verdadera originalidad decorativa y simbólica a la torre conventual. A juicio de las imágenes conservadas de la torre anteriores a 1986 solo es posible tener plena certeza de los motivos decorativos de cinco de los ocho paneles de azulejos dispuestos en la cúpula. Comenzando la descripción por el lado oeste en dirección sur-este-norte diferenciamos los siguientes motivos y modelos: Cruz, desconocido, cáliz, desconocido, desconocido, damero o ajedrezado, líneas en zig-zag en sentido vertical, red o retícula. El tambor del que arranca la cúpula presentaba una decoración original de damero cuyo diseño de imitación se mantiene en la actualidad.

\subsubsection{Tipología}

Las torres barrocas construidas en Andalucía durante el siglo XVIII se han convertido en señalados elementos del paisaje urbano de nuestra tierra, con un especial protagonismo en las poblaciones de las provincias occidentales. El elevado número de torres levantadas en aquella centuria es una característica de la arquitectura barroca. Muchas de estas construcciones se vieron impulsadas por causa y efecto de importantes y desgraciados sucesos naturales como el ya citado huracán de 1722 y otros, aún más conocidos, como el terremoto de 1755. 
Analizando la presente tipología arquitectónica hemos de recordar que hasta el siglo XVI el modelo de torre mudéjar será el que predomine dentro de la arquitectura eclesial. Con la implantación de postulados pertenecientes a la estética renacentista tiene lugar un evidente desarrollo de las espadañas, las cuales, suponen un contrapunto de las torres finalizadas en campanarios, deudoras del arquetipo creado por Hernán Ruiz para la Giralda de la Iglesia Mayor hispalense ${ }^{18}$. Frente a este predominio de las espadañas en el siglo XVII y ante la escasez del modelo de fachada entre dos torres, el siglo XVIII presenta como novedad una abundancia de torres exentas construidas en ladrillo y adornadas con cerámicas vidriadas. Algunas de ellas alcanzaron los cincuenta metros de altura erigidas también con un elevado costo económico. Antonio Bonet Correa señala la existencia de dos tipos claramente definidos. Por un lado encontramos la torre de gran caña o fuste de origen islámico inspiradas en el modelo sevillano de la Giralda y, por otro, la torre campanario de cuerpos decrecientes con dominantes cristianos en la composición y empleo de los órdenes clásicos ${ }^{19}$.

La torre de la merced de Rota presenta unas particularidades que permiten la distinción, no ciñéndose de manera expresa a ninguno de los dos tipos o modelos dominantes dentro de la arquitectura barroca andaluza del siglo XVIII. Concretando un poco más, la torre mercedaria de Rota se aproxima en mayor medida al segundo tipo, destacando su severa elegancia completada con una coqueta cubierta cupulada. Este último aspecto le dota de mayor singularidad a nuestra torre debido al frecuente uso del chapitel como remate habitual de la mayoría de las torres levantadas en aquella época. Por último, la torre de la Merced puede llevar a gala ser una de las arquitecturas pioneras en su tipo, gracias a la temprana cronología de la que data, dentro de la tipología señalada en la arquitectura barroca dieciochesca.

\subsection{Las restauraciones}

Los primeros pasos dados con la intención de restaurar la Torre de la Merced fueron protagonizados por el entonces Alcalde de Rota Don

18 SANCHO CORBACHO, A. Arquitectura barroca sevillana del siglo XVIII. Sevilla, 1984, pp. 30-32.

19 BONET CORREA, Antonio. Andalucía Barroca, Arquitectura y Urbanismo. Barcelona, 1978, p. 215. 
Antonio Maña Zafra. En una carta personal dirigida a Don Florentino Pérez Embid, a la sazón Director General de Bellas Artes dependiente del Ministerio de Educación y Ciencia, el primer edil exponía sus razones para lograr el apoyo económico necesario para llevar a cabo el citado proyecto. En dicha misiva, fechada en Rota a 27 de junio de 1969, el alcalde Sr. Maña Zafra expone la trascendencia que tenía la torre para la villa y sus virtudes como monumento artístico, instando finalmente a una pronta y necesaria restauración. En este mismo sentido, se produce una interesante correspondencia entre los anteriormente citados y el profesor Don José Luis de la Rosa Domínguez con la intención de poder agilizar todo el proceso. En una de las cartas escritas por Pérez Embid a los interesados se expone que el asunto en cuestión ha pasado a la Comisaría de Patrimonio Artístico. Sin embargo, en las últimas cartas registradas y fechadas en 1970, se dice que el asunto ha quedado congelado," en suspenso sin saber la causa" 20.

\subsubsection{La restauración de 1972}

Desde una perspectiva documental, el proceso restaurador comienza con un breve informe firmado por Don Fernando Contreras Moreno, arquitecto municipal, en relación con la restauración y consolidación de la Torre de la Merced. De manera concisa, el arquitecto expone que "Debido al mal estado y a las últimas y pertinentes lluvias, es de total urgencia la restauración y consolidación de dicha Torre, ya que existe peligro de derrumbamiento de alguna zona de la misma, con el consiguiente peligro para los peatones que circulen por dicha $z o n a^{\prime \prime}$. A la vista de dicho informe técnico, el Secretario General de la corporación municipal Don Juan Ulpiano Fernández Fernández "entiende que parece acreditada la urgencia y en su consecuencia contratar las correspondientes obras directamente". Ambos testimonios figuran conjuntamente en un mismo folio, fechados en Rota el día 23 de marzo de $1972^{21}$, hecho que denota el interés previo de los poderes políticos locales de afrontar con urgencia y celeridad la restauración de la antigua construcción mercedaria.

\footnotetext{
20 Archivo Municipal de Rota. Expediente 619, Negociado 58. Ayuda económica para obras de reconstrucción de la Torre de la Merced. L-3.326. 1969.

21 Archivo Municipal de Rota. Expediente del Negociado de Obras Municipales. $N^{\circ}$ 88/72. Restauración de la Torre de la Merced. 1972.
} 
El día cuatro de abril siguiente se reúne la Comisión Municipal Permanente del Ayuntamiento, en la que se tomaron los siguientes acuerdos. En primer lugar se estimo necesario"declarar la urgencia de contratación de la expresada obra". El segundo punto refleja el acuerdo de" aprobar los correspondientes pliegos de condiciones para la contratación de las mismas". El tercer punto señala la intención de "contratar directamente con Don Manuel Seijo Calvo, Maestro Cantero del Puerto de Santa María, por el precio del proyecto ascendente a la suma de doscientas cuatro mil trescientas setenta y una pesetas con ocho céntimos" 22 .

A pesar de las urgencias que sugieren las palabras anteriores, no será hasta varios meses después cuando se produzcan avances en el proceso restaurador, según se extrae del telegrama expedido por orden del Alcalde de Rota al anteriormente citado maestro cantero portuense. El texto de dicho telegrama es el siguiente: "Para asunto de interés, ruegole venga urgentemente", fechado en Rota el día 24 de noviembre de $1972^{23}$.

Los trabajos de restauración a los que es sometida la Torre de la Merced se conocen de forma detallada gracias a la existencia de una certificación de obras fechada en el mes de abril de 1974, firmada por el arquitecto municipal Don Fernando Contreras Moreno y dada su conformidad firmada por el contratista Don Manuel Seijo Calvo ${ }^{24}$. En esta certificación se detallan cinco intervenciones o trabajos diferenciados. El primero de ellos trata de la"reparación cantería remate superior de la cúpula y reposición de azulejos" cuyo costo se cifra en treinta y dos mil pesetas. El segundo es un trabajo de"restauración total con cantería de las cuatro caras comprendidas entre las cornisas superior e interior de la planta del campanario" por el que abonan de acuerdo al presupuesto un total de noventa mil pesetas. Un tercer trabajo de "relabrado de los ángulos de las esquinas N.O, S.O., S.E. y reposición de

22 Archivo Municipal de Rota. Expediente del Negociado de Obras Municipales. $\mathrm{N}^{\circ} 88 / 72$. Restauración de la Torre de la Merced. Certificado expedido por el Secretario General del Ilustrísimo Ayuntamiento de la Villa de Rota. 15 de abril de 1972.

23 Archivo Municipal de Rota. Expediente del Negociado de Obras Municipales. $\mathrm{N}^{\circ} 88 / 72$. Restauración de la Torre de la Merced. Telegrama con sello de registro general salida ${ }^{\circ} 10932$.

24 Archivo Municipal de Rota. Expediente del Negociado de Obras Municipales. N ${ }^{\circ}$ 88/72. Restauración de la Torre de la Merced. Primera y única certificación de las obras de restauración y consolidación de la torre del compás del convento o de la merced. Abril de 1974. 
3,50 metros de ángulo en la esquina N.E.". El coste de estos trabajos asciende a diez mil pesetas. Un cuarto trabajo de"restauración portada p[lanta] baja cara oeste" que se presupuesta en doce mil quinientas pesetas. El quinto y último trabajo consignado es una"obra de albañilería en picado y saneado y andamiaje" cuyo coste se cifra en veinticinco mil pesetas. Los cinco trabajos indicados suman un coste total de ciento sesenta y nueve mil quinientas pesetas. A este montante total de la ejecución material de la obra se le añade el 15\% de Beneficio Industrial (25.425 pesetas) así como los honorarios del arquitecto (7.304,68 pesetas) y aparejador (2.141,40 pesetas). Todo ello computa una cantidad final de $204.371,08$ pesetas que corresponde con la cantidad presupuestada al inicio de la restauración de la torre ${ }^{25}$.

Hemos de suponer que dichos trabajos se realizarían con celeridad si nos atenemos a la fecha de 1972 que consta en la placa conmemorativa situada en el muro norte de la torre. Sin embargo y a tenor de los documentos consultados, la penuria económica de las arcas municipales imposibilitó el pago inmediato de la obra como se desprende de la fecha de certificación antes mencionada. Por dicho motivo, la corporación local acordó meses más tarde, en concreto el once de junio de 1974"interesar al Banco de Crédito Local...la remisión de los fondos correspondientes para el abono de la citada certificación al mencionado contratista" 26 .

La restauración material de la torre se completó con la colocación de tres señeras campanas de Rota. La primera perteneció al antiguo reloj del Ayuntamiento. Otra, sin uso en aquel momento, procedía del antiguo Hospital de la Caridad y ermita de San Sebastián. La tercera y de menor tamaño que las anteriores fue donada por el cura párroco de Nuestra Señora del Carmen Don Juan González Lagomazzini ${ }^{27}$. Otra aportación fue la colocación de una cruz de hierro como remate final de la torre.

El proceso restaurador supone un primer paso para devolver al edificio esplendores pasados, pero también representa algunos

25 Id.

26 Archivo Municipal de Rota. Expediente de Obras Municipales N ${ }^{\circ}$ 88/72. Restauración de la Torre de la Merced. Certificado de acuerdos de la Comisión Permanente celebrada el once de junio de 1974. Firmada por el Secretario General Don Juan Ulpiano Fernández Fernández. 14 de junio de 1974.

27 De la Rosa Domínguez, José Luis. El Convento de la Merced de Rota y la Virgen de la Escalera. Rota: Fundación Alcalde Zoilo Ruiz Mateos, 1981, p.46. 
cambios sutiles de su aspecto original. Por un lado se constata una clara voluntad de respetar el proyecto original recuperando el aspecto inicial de los vanos de ambos cuerpos de campanas, tapados hasta la mitad de su altura con la intención de dotar de firmeza a la construcción ante las acometidas de los fuertes vientos que dominan en la zona. También es de justo reconocimiento la recuperación de la linterna así como el mantenimiento de los paños de azulejos originales de la cúpula.

En el debe de la restauración hemos de señalar dos pequeños cambios a tener en cuenta. El primero y de mayor importancia reside en la modificación del vuelo de la cúpula, puesto que en algunas fotografías anteriores a la fecha de restauración, parece apreciarse este hecho levantada sobre el tambor y el inicio de la cornisa del segundo cuerpo de campanas. Tras la restauración las líneas son inequívocamente rectas quitando parte de gracia y dinamismo al modelo primitivo. La segunda modificación es el añadido de piezas cerámicas en los plintos del primer cuerpo de campanas y en el perímetro del tambor de la cúpula.

\subsubsection{La restauración de 1986}

A mediados de los años 80 tienen lugar nuevos trabajos de restauración en la Torre de la Merced. El motivo de esta intervención era hacer realidad el proyecto de convertir la torre en salón cultural y sede de exposiciones para Rota.

Previamente a la realización de este proyecto se abre expediente con la redacción de una ficha técnica del estado constructivo del edificio y elementos arquitectónicos a cargo de la Dirección General de Bellas Artes ${ }^{28}$. En la citada ficha, la torre recibe una calificación legal de estar incluida en Conjunto Histórico-Artístico e incluida también en Inventario. El documento presenta una descripción detallada de la torre y sus lindes, aunque el expediente no conserva los documentos fotográficos a los que hace referencia. Además añade accesos, servicios externos, características principales, valores arquitectónicos

28 Archivo Municipal de Rota. Expediente n ${ }^{\circ}$ 40/85 V-1 Instruido para contener todo lo relativo a la contratación de las obras de restauración de la Torre de la merced para Sala de Exposiciones de Rota. L-5.057. Año 1985. 
fundamentales, documentación gráfica y croquis del edificio. El estado de conservación apunta que la cimentación está en "buen estado", mientras que otros aspectos como son los elementos ornamentales, cubiertas y azulejería, entre otros, se hallan en "mal estado". La cantería requiere una "pequeña reparación". El estado de conservación concluye que su "conservación en general es deficiente no obstante son necesarias obras de acondicionamiento interior, obras de restauración exterior y demolición parcial del forjado, cuya descripción se detalla en la memoria del proyecto básico y de ejecución". El presupuesto global de la obra alcanza la cantidad de seis millones novecientas veintitrés mil novecientas cuarenta y cinco pesetas ${ }^{29}$. El proyecto básico de ejecución, restauración y acondicionamiento de la torre del convento mercedario incluye planos de las plantas, alzado y sección de edificio en su estado actual y reformado, firmados por el arquitecto Jesús Rodríguez Sainz y fechados en Cádiz el mes de enero de $1984^{30}$.

En sus Anales de la Villa de Rota, el actual cronista Don José Antonio Martínez Ramos expone que, en esta ocasión, los trabajos "consistieron en la adecuación de la planta baja como salón cultural, a cuyo objeto se procedió a la demolición de las techumbres de la nave anexa, cuyo mal estado requería su urgente sustitución. Asimismo se renovó en su totalidad la solería, sustituyéndola por otra de mármol blanco. Respecto a la cúpula se procedió a la retirada de los azulejos que la cubrían, que fueron sustituidos por nuevas piezas. Asimismo, se procedió a la limpieza de las piedras de sus fachadas, aplicando un tratamiento herbicida a las molduras, y sustituyendo los sillares más dañados por otros nuevos" ${ }^{\prime 31}$. El mismo autor indica que estos trabajos contaron con un presupuesto de 7.568.880 pesetas, superior a la cifra señalada en la anterior ficha técnica y financiada en su totalidad por la Consejería de Cultura de la Junta de Andalucía.

El aspecto más discutible de la restauración es, sin duda alguna, la sustitución de los azulejos originales de la cúpula cambiados por otros nuevos. El señor Martínez Ramos expresa su opinión al respecto señalando que "aún reconociendo la idoneidad de los trabajos realizados, no podemos menos que lamentar la desaparición de parte de los últimos restos que quedaban del viejo convento, tales como la techumbre

\footnotetext{
$29 \quad I d$.

30 Id.

31 Año de 1986.
} 
de la antigua crujía y de los distintos dibujos que formaban los azulejos de la cúpula"32.

En el Boletín Municipal, en un artículo relativo a la restauración de la Torre de la Merced se indica el hecho de que "la cúpula contará con azulejos similares a los primitivos respetando la línea establecida en su construcción originaria"33.

Sin embargo, la realidad actual dista en largo trecho de las buenas intenciones anteriormente mencionadas por el órgano de comunicación municipal. Los azulejos que hoy pueden verse carecen de la belleza, variedad y valor artístico de los primitivos, presentando un diseño homogéneo y repetitivo. También es notorio el hecho de la supresión de los símbolos religiosos (la cruz, el cáliz) y la variedad de temas geométricos allí representados. A nuestro parecer, la mejor solución atendiendo al máximo respeto hacia nuestro patrimonio histórico-artístico hubiera sido renovar aquellas piezas deterioradas, inservibles o desaparecidas por otras nuevas de imitación. Cierto es que a tenor de las imágenes conservadas el desgaste de los azulejos era importante, pero no encontramos suficientes razones que justificaran un cambio completo de toda la obra.

Años más tarde, la idea de convertir la Torre de la Merced en un espacio museístico seguía vigente procurando dar una solución práctica y funcional al edificio. En 1996 se produce la apertura de un expediente con tal motivo y finalidad, realizándose un dossier fotográfico del exterior e interior de la torre. Sin embargo, esta nueva propuesta quedaría desechada posteriormente ${ }^{34}$.

Hoy en día, las dependencias interiores de la torre y sala anexa son utilizadas como sede del Consejo de Hermandades y Cofradías de Rota.

\subsubsection{Restauración de 2009}

El último proceso restaurador acaecido en la torre tiene lugar en el año 2009. Los trabajos de restauración afectaron a la torre propiamente dicha, como también a la galería situada en la parte posterior y la nave lateral con dos cúpulas. Las obras se dirigen a la conservación

\footnotetext{
Anales de la Villa de Rota. Año de 1986. Nota a pie de página.

Boletín Municipal, número 2, 1987, pp. 10-11.

Archivo Municipal de Rota. Expediente Museo en la Torre de la Merced.

Delegación de Cultura. 1996.
} 
de la arquitectura con labores de saneamiento de los sillares exteriores, eliminación de mortero de cemento existentes y su sustitución por otros morteros naturales, reparación de los ornamentos cerámicos de la torre y de la cruz de hierro de la torre. También se reparó el portón y se instaló un pararrayos nuevo. El presupuesto para todas estas labores de restauración y equipamiento alcanzó los 280.000 euros $^{35}$.

\section{CONCLUSIONES}

La primitiva torre del desaparecido convento de la Merced Descalza de Rota se construyó en los mismos años que las dependencias e iglesia del conjunto, entre los años 1604 y 1624, no siendo posible una mayor delimitación cronológica. El día 26 del mes de octubre de 1722 un devastador huracán asoló las costas de Rota destruyendo la torre y causando graves perjuicios a los habitantes de la villa. La Comunidad de frailes mercedarios emprende la restauración material de edificio y especialmente de la nueva torre que se construye entre 1723 y los primeros meses de 1724, contando para ello con la colaboración de fieles devotos que ayudan económicamente en la reconstrucción a cambio de sufragios. Como material constructivo se emplearon las piedras de las canteras cercanas de Bahifora cuya extracción había sido permitida por el Cabildo de la Villa.

Esta construcción, de acuerdo a su cronología, es una de las primeras torres erigidas en Andalucía durante el siglo XVIII momento en el que adquiere gran importancia como modelo o tipo constructivo con personalidad propia dentro de la arquitectura de aquella época.

La Torre de la Merced se inscribe dentro de los postulados estéticos del llamado Barroco clásico y constituye un valioso ejemplo arquitectónico de la continuidad clasicista mantenida durante el siglo XVIII. Ello fue posible gracias a la doble influencia de la tratadista principalmente venida de Italia como Serlio o Vignola y la presencia real de grandes construcciones que sostienen el eco del clasicismo en una época de auge de las formas del denominado barroco triunfal y castizo. Este mantenimiento de elementos clásicos, de gran solidez constructiva y escasa ornamentación, es canalizado en buena medida por la presencia activa de arquitectos, alarifes y tracistas

35 PRADOSVILLAR, Olga. "La Torre de la Merced inicia su proceso de restauración" en Andalucía Información. Publicado el 4 de junio de 2009. 
pertenecientes a diferentes órdenes religiosas, así como a la presencia de arquitectos formados bajo el influjo de la arquitectura cortesana.

En este sentido hemos querido plantear una hipótesis de autoría de la Torre de la Merced dentro de la orbita estilística de Alonso Moreno, maestro mayor de la casa ducal de Arcos, cargo que desempeña desde 1682 hasta su muerte acaecida en Marchena en 1725. Las coincidencias cronológicas y el hecho de servir durante tantos años a los duques permiten situarlo dentro del contexto de la obra objeto de estudio. Además de las circunstancias coincidentes antes señaladas producto del contexto cronológico, profesional y de su servidumbre señorial, existen otros factores y elementos señalados que contribuyen a una posible atribución partiendo del análisis formal de las construcciones basadas en un marcado clasicismo, severo pero elegante, que tiene su inspiración en las proporciones clásicas y en los tratados teóricos de arquitectura de los siglos XVI y XVII. En este caso la arquitectura de la torre mercedaria es un claro precedente y una obra adelantada al posterior clasicismo que caracterizará la arquitectura gaditana de la segunda mitad del siglo XVIII.

El obligado abandono del edificio por parte de la comunidad religiosa tras la desamortización decimonónica y el azote de vientos y otros elementos erosivos naturales provocaron con los años el paulatino deterioro de la torre. A ello habría que sumar la demolición de la práctica totalidad del complejo conventual, a excepción de la propia torre y de dos capillas anejas, que ofrecen hoy una imagen de soledad muy alejada de su concepción primera y fundacional. Los daños materiales de la torre obligaron a la intervención de los poderes públicos para lograr su recuperación patrimonial siendo restaurada en tres ocasiones, destacando por su calado e importancia las que tuvieron lugar en los años 1972, 1986 y más recientemente en 2009. 


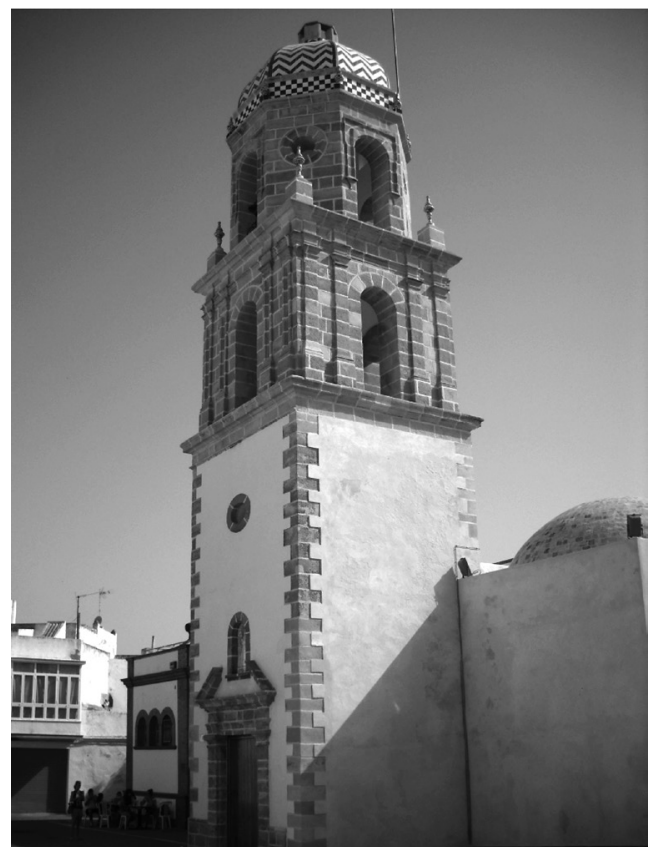

Figura 1. Torre de la Merced. Fachadas oeste y sur.

Foto del autor

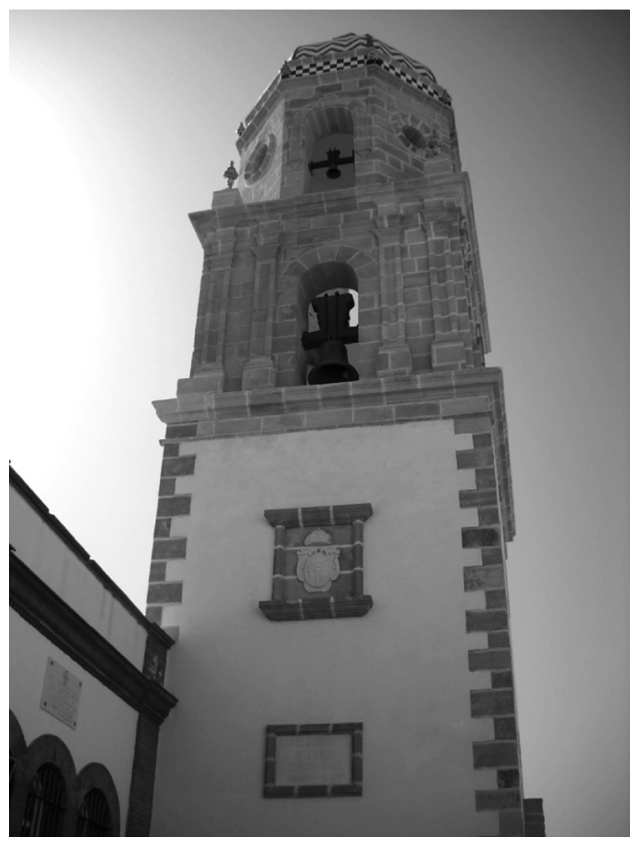

Figura 2. Torre de la Merced. Detalle de la fachada norte. Foto del autor. 
Figura 3. Torre de la Merced. Fachada sur. A la derecha se observa una de las capillas anejas. Foto del autor.

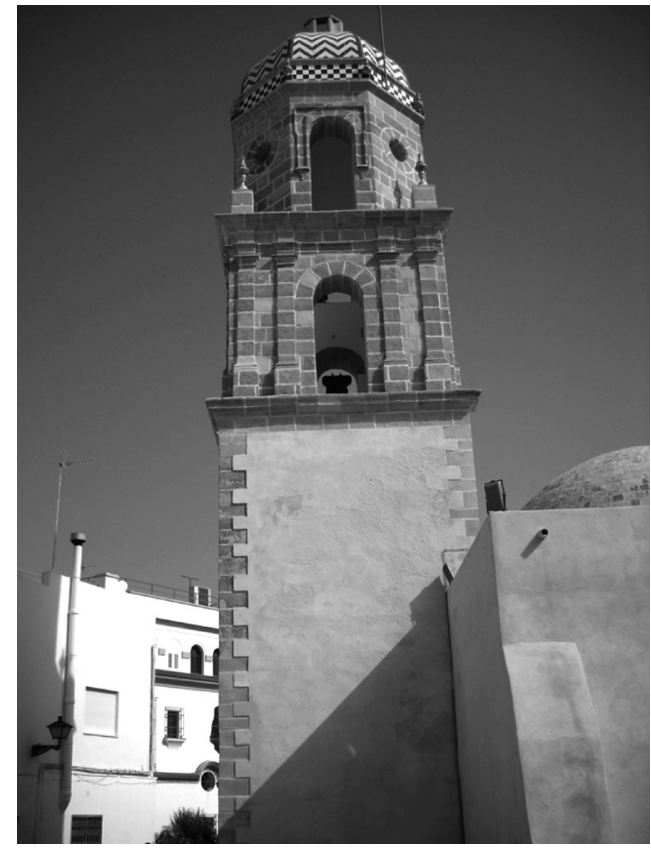

Figura 4. Torre de la Merced. Portada. Foto del autor.

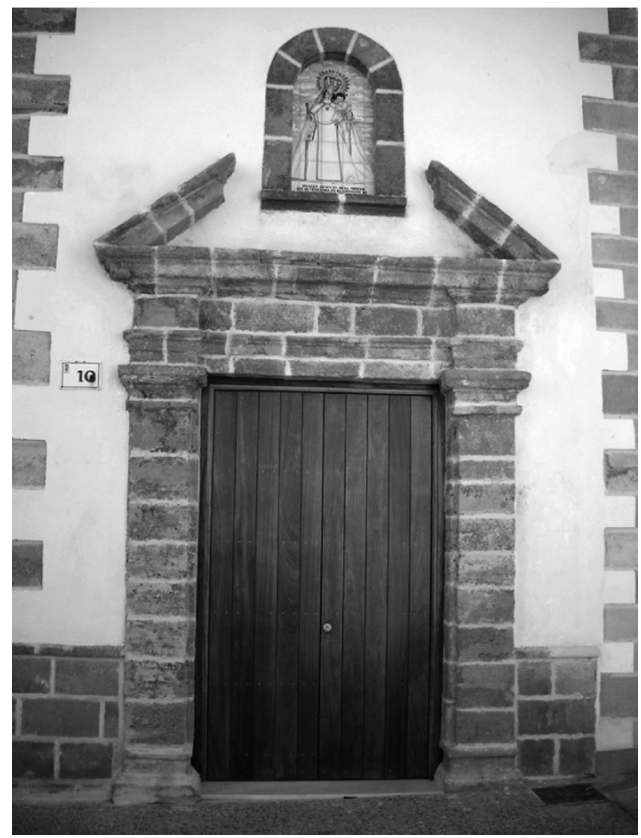




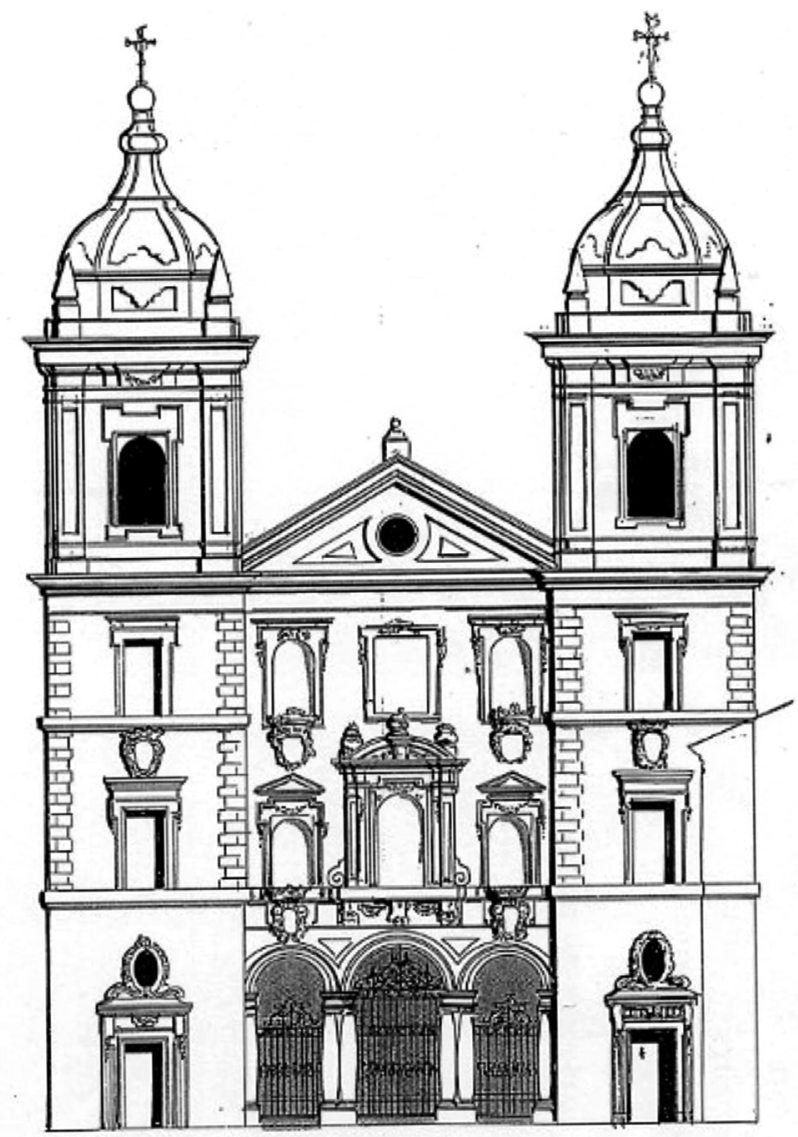

Figura 5. Portada de la Iglesia de San Agustín. Marchena. Diseño de Alonso Moreno. Dibujo tomado de RAVÉ PRIETO, Juan Luis. Op. Cit, pp. 707-719. 